\title{
Carnaval, combate y jerarquía entre los hinchas que forman una barra brava de Bogotá*
}

\author{
John Castro Lozano**
}

- El artículo es un avance de la tesis de grado —intitulada ¡Yo soy azul! La imitación y el aguante entre hinchas en Bogotá - desarrollada por el autor en la línea de investigación en Subjetividades, Diferencias y Narrativas en el Doctorado en Estudios Sociales de la Universidad Distrital Francisco José de Caldas.

** Candidato a doctor en Estudios Sociales en la Universidad Distrital Francisco José de Caldas, magíster en Estudios Sociales de la Universidad Pedagógica Nacional, y sociólogo de la Universidad Nacional de Colombia. Actualmente es profesor en la Universidad Antonio Nariño (sede Bogotá). Correo electrónico: alexandercastro1981@gmail.com https://orcid.org/0000-0001-8397-7690

Fecha de recepción: 8/05/2020. Fecha de aceptación: 24/08/2020. 


\title{
Carnaval, combate y jerarquía entre los hinchas que forman una barra brava de Bogotá
}

\section{RESUMEN}

El artículo pretende comprender el carnaval y el combate entre los hinchas que forman una barra brava en Bogotá, expresiones y comportamientos que constituyen el orden interno y la jerarquía. En este aspecto, el trabajo de campo etnográfico fue realizado desde el primer semestre de 2017 hasta el primer semestre de 2018, con hinchas de Millonarios Fútbol Club que forman Blue Rain. El trabajo de campo etnográfico posibilita «estar ahí» con los sujetos y el grupo social para describir y participar en las diferentes prácticas en las que intervienen. De este modo, el artículo se organiza de la siguiente manera: primero, la introducción, que permite contextualizar el problema de investigación; segundo, la metodología y el enfoque de la investigación; tercero, la participación en la festividad y la permanencia en las peleas, demostrando el aguante, y cuarto, el orden interno y la jerarquía. Por último, son expuestas algunas conclusiones.

Palabras clave: carnaval, combate, socialización, jerarquía, barra brava.

Carnival, combat and hierarchy among the supporters that form a «barra brava» in Bogotá

\begin{abstract}
The article tries to understand the carnival and the combat between the supporters who form a «barra brava» in Bogotá, expressions and behaviors that constitute internal order and hierarchy. In this aspect, the ethnographic fieldwork was carried out from the first semester of 2017 to the first semester of 2018, with supporters of «Millonarios Fútbol Club» who form Blue Rain. Ethnographic fieldwork makes it possible to «be there» with the subjects and the social group to describe and participate in the different practices in which they intervene. In this way, the article is organized as follows: first, the introduction, which allows contextualizing the research problem; second, the research methodology and approach; third, the participation in the festivity and permanence in fights, demonstrate the "aguante»; and fourth, the socialization processes and the constitution of the hierarchy. Finally, some conclusions are exposed.
\end{abstract}

Keywords: carnival, combat, socialization, hierarchy, «barra brava». 


\section{INTRODUCCIÓN}

En Colombia, las principales barras bravas se constituyeron durante la década de 1990 en Bogotá, Cali, Medellín, Barranquilla, Manizales, Bucaramanga, Neiva, Pereira e Ibagué, alrededor de los equipos que participaban en el campeonato de primera división del fútbol profesional colombiano (FPC). Las barras bravas expusieron innovadoras formas de apoyo a los equipos de fútbol, usando banderas $\left(\right.$ trapos $\left.^{1}\right)$, sombrillas, papel, humo de colores, pirotecnia, aplausos, saltos y canciones adaptadas al contexto del fútbol. Asimismo, los enfrentamientos entre los hinchas de distintos clubes — poco a poco- se normalizaron, al mostrar una frecuencia continua y la participación de centenares de hinchas, en el interior y en el exterior de los estadios. Esa regularidad e intervención permitió un proceso de consolidación de las barras bravas.

En cada partido, en la tribuna ocupada por la barra brava, se pueden observar los trapos colgados, las sombrillas levantadas, el papel lanzado, el humo de colores y la pirotecnia encendida. Además, los hinchas aplauden, saltan y cantan durante el juego. De esta manera, exhiben su identidad futbolística y, además, es su forma de alentar a su club. Asimismo, antes y después del partido, es posible escuchar burlas, insultos, desafíos y amenazas dirigidas a los hinchas rivales. En algunas ocasiones, al encontrarse cerca del estadio, en barrios o en carreteras, se pueden enfrentar: peleas en las que es probable el uso de la cabeza, los brazos y las piernas. También es posible usar piedras, palos de madera, varillas, e incluso, cuchillos y machetes. Desde la posición de los hinchas, integrantes de las barras bravas, lo festivo y lo violento se denomina carnaval y combate, respectivamente. Es la perspectiva emic.

La participación en la festividad y la permanencia en las peleas permite entender las formas de constituir el orden en la barra brava. En otras palabras, la jerarquía se establece a partir de la intervención en el carnaval y la constancia en el combate; alentar al equipo y pelear contra los rivales definen la autoridad, la posición y las responsabilidades entre los hinchas que forman la barra brava. Una autoridad, una posición y unas responsabilidades que solamente se pueden conservar si en cada reunión, en cada partido o en cada viaje, la participación en el carnaval y la permanencia combate pueden ser verificadas por los hinchas que forman la barra brava. De lo que se trata es comprender la perspectiva emic y construir una interpretación etic sobre el orden interno y la jerarquía —es decir, lo político— a partir de la aspiración de los hinchas por ejercer una autoridad, alcanzar una posición y logar unas responsabilidades admitidas en la barra brava.

\footnotetext{
1 Las nociones de los hinchas son resaltadas en cursiva.
} 
De este modo, el propósito del artículo es comprender el carnaval y el combate entre los hinchas que forman una barra brava en Bogotá, expresiones y comportamientos que posibilitan el orden interno y la jerarquía. El texto se organiza de la siguiente manera: primero, la presente introducción, que permite contextualizar el problema de investigación; segundo, la metodología y el enfoque de la investigación; tercero, la participación en la festividad y la permanencia en las peleas, demostrando el aguante, y cuarto, el orden interno y la jerarquía. Por último, en este artículo se entiende por barras bravas a los grupos organizados de hinchas (GOH). Desde una posición externa, son promotores de expresiones festivas y comportamientos violentos en el contexto del fútbol. En Colombia, la denominación de barras bravas no es positiva y tampoco es negativa, pues depende del uso que le otorguen los hinchas, la opinión pública, las autoridades deportivas y civiles o los periodistas.

\section{De la METOdología Y EL ENFOQUe}

Este artículo presenta algunos de los resultados del trabajo de campo etnográfico — realizado en 2017 y en el primer semestre de 2018 — con hinchas de Millonarios que forman Blue Rain. La descripción y la participación se desarrolló antes, durante y después de, aproximadamente 38 encuentros futbolísticos jugados por Millonarios en el estadio Nemesio Camacho «El Campín» y en el Metropolitano de Techo. También, en diversas reuniones (públicas y privadas) de los hinchas que integran la barra brava. De acuerdo con Geertz (1989), el tiempo transcurrido me permitió «estar allí» o, mejor, «estar ahí» con, particularmente, los hinchas que forman Blue Rain: en las reuniones, en las tribunas y en las calles. En otras palabras, al «estar ahí» con los hinchas conseguí adentrarme en el contexto que permite desenvolver las múltiples situaciones de los hinchas en la barra brava. Asimismo, fue posible distinguir rutinas y costumbres, horarios y lugares de encuentro, formas de vestir y objetos de importancia, entre otros.

De lo que se trata es de entender la cultura en su contexto, pues los sucesos sociales, las formas de comportarse, las instituciones y los procesos sociales poseen un significado específico. Así, se busca interpretar una serie de interpretaciones de los actores-testigos (Geertz, 2003). En otras palabras, «estar ahí» consiste en la comprensión y la interpretación de lo que comprenden e interpretan los hinchas de Millonarios que forman Blue Rain sobre lo que ellos practican antes, durante y después de los partidos en el estadio Nemesio Camacho "El Campín» y en el Metropolitano de Techo de Bogotá. Por eso, el acercamiento a los sujetos y al grupo social es un paso fundamental: se hace ineludible estar al tanto de los horarios en los que se encuentran, frecuentar los lugares que ocupan, identificar quiénes lo forman, las maneras de relacionarse y su organización interna y, además, elaborar un registro de las actividades de mayor regularidad y las rutinas que se llevan a cabo. 
En mi ejercicio de investigación fue fundamental diferenciar a los hinchas que forman esa barra brava de Millonarios, las formas de socializar entre ellos y con los sujetos ajenos al grupo social, sus formas de individualización y de organización. En otras palabras, la perspectiva etic le otorga relevancia a la descripción del investigador. Igualmente, la relevancia de la participación en las dinámicas particulares de las reuniones; escuchar y colaborar de las actividades de la barra brava; en las tribunas, cantar y saltar durante el partido; y en las calles, marchar camino al estadio y si es posible, presenciar los enfrentamientos entre los hinchas, aunque eso implica un riesgo para el investigador. «El observador participante hace centro en su carácter de observador externo, tomando parte de actividades ocasionales o que sea imposible eludir» (Guber, 2001, p. 73). Además, la perspectiva emic permite complementar lo presenciado, es decir, son básicas las voces de los hinchas, por ejemplo, a través de sus testimonios.

De esta manera, Blue Rain se encuentra, principalmente alrededor de los partidos de Millonarios jugados, principalmente en el estadio Nemesio Camacho «El Campín", pues el club disputa sus juegos como local en este escenario deportivo. Los hinchas que forman Blue Rain se ubican en la tribuna lateral sur alta y desde allí cantan y saltan durante el encuentro futbolístico, buscando, a través de esas manifestaciones, apoyar al grupo de jugadores de su equipo. Además, realizan reuniones —en días hábiles de la semana- cerca del estadio, encuentros que les permiten organizar las variadas manifestaciones del siguiente partido e incluso, programar los viajes siguiendo al club cuando juega de visitante. En algunas ocasiones, los hinchas de Millonarios que forman Blue Rain deben asumir las emboscadas de los hinchas rivales y asumirlas implica permanecer en el lugar del ataque, es decir, no huir de los aficionados de otros equipos, respondiendo de forma semejante al ataque perpetrado.

El trabajo de campo etnográfico implica observar las prácticas de los sujetos en su grupo social, y en las ocasiones posibles, intervenir y reproducir esas vivencias. En este sentido, el trabajo de campo etnográfico con hinchas de Millonarios que forman Blue Rain posibilita ir a las reuniones a escuchar sus propuestas para materializar en el siguiente partido o en la tribuna a saltar y cantar como formas de apoyar a su club, es decir, en las reuniones y en las tribunas es posible participar sin mayores dificultades. No obstante, el trabajo de campo etnográfico en la calle puede mostrar al investigador algunas limitaciones ya que es posible que la barra brava sea emboscada por hinchas rivales o sean detenidos y agredidos por parte de la policía. En otras palabras, en la calle son probables las lesiones corporales, pues los hinchas buscan una victoria en el enfrentamiento y la policía pretende someterlos, ejerciendo más violencia que la practicada por los hinchas.

En este aspecto, el desarrollo del trabajo de campo etnográfico fue orientado a partir de las experiencias de algunos investigadores argentinos, quienes realizaron 
su exploración con GOH. De este modo, Aragón (2007) —realizó su investigación con La Butteler del Club Atlético San Lorenzo de Almagro— sostiene: «No fueron pocas las veces en que me vi involucrado en situaciones en las cuales era superado por los acontecimientos y en general sólo atinaba a imitar a los que me rodeaban» (p. 23). Asimismo, Garriga (2012) — con la banda del Club Atlético Huracánseñala: «Hacer una etnografía con una hinchada de fútbol, según mi percepción, era sumergirse en un mundo de peligros y riesgos» (p. 15).

Y Cabrera (2017) — con Los Piratas del Club Atlético Belgrano- afirma: «El 'estar alli' en nuestros casos involucra riesgos que muchas veces pueden tener desenlaces no deseados. La mera presencia — real o imaginada - de peligros latentes coloca la emocionalidad del investigador en un estado de alerta permanente» (p. 59). De esta manera, las reflexiones de los investigadores argentinos (en torno al trabajo de campo etnográfico, especialmente lo relacionado con los incidentes violentos) fueron relevantes en tanto que permitieron comprender que, es el investigador quién decide qué hace, qué prácticas sigue y en cuáles se involucra. En este caso, el trabajo de campo etnográfico, con barras bravas o GOH, implica observar y participar en una serie de situaciones o eventualidades que pueden amenazar la integridad física del investigador, pero es él quien decide si se involucra o no. Si decide observar y no participar, puede ser ilustrativo manifestar las sensaciones que lo motivaron a no involucrarse. Y si decide participar, puede ser ilustrativo contar las sensaciones que lo motivaron a involucrarse.

De otra parte, debo señalar que yo soy hincha de Millonarios y formé en la barra brava Comandos Azules \# 13, entre 1997 y 1999. En ese periodo salté y canté sin parar, participé en los recibimientos al equipo, en diferentes ocasiones viajé (por carretera) a los juegos de visitante y, ocasionalmente, hice frente a la invasión del territorio por los rivales. Por eso, la barra brava escogida para desarrollar mi trabajo de campo etnográfico fue Blue Rain de Millonarios. La elección no fue repentina o casual, fue intencional, y por eso debo decirlo, quizá a modo de confesión:

Más que una confesión se trata de un reconocimiento. Usted estudia indígenas: ¿qué tienen que ver ellos con usted? Usted estudia campesinos, homosexuales, prostitutas: ¿qué tan cercano o lejano está usted de estos sujetos? ¿Usted es afrodescendiente?, ¿usted es racista?; ¿̇usted es homosexual, puesto que estudia homosexuales?, ¿usted estudia la prostitución porque frecuenta «trabajadoras sexuales»? ¿Qué interés tiene usted de presentar una suerte de visión reivindicativa del otro? Surge nuevamente la gran pregunta antropológica: jesa ciencia de los otros puede seguir siendo ciencia de los otros, cuando los otros están dentro de nosotros? (Sanabria, 2009, p. 20).

Así, el trabajo de campo con Blue Rain de Millonarios fue posible a través de mi afición futbolística y mi antigua participación en la barra brava; es decir, Millonarios 
y Blue Rain no son ajenos o extraños a mí, estoy familiarizado con el club y el grupo social. En este aspecto, de acuerdo con Goldenberg (1999): "Quanto mais o pesquisador tem consciência de suas preferências pessoais mais é capaz de evitar o bias, muito mais do que aquele que trabalha com a ilusão de ser orientado apenas por considerações científicas» (p. 45).

En relación con eso, distingo el emblema, los colores del club y la historia deportiva de Millonarios, pues son parte de mi sentido de pertenencia en el contexto del fútbol, e identifico a algunos hinchas, unos que aún forman en las barras bravas de Millonarios (Blue Rain o Comandos Azules) y otros, que ya no lo hacen. Sin embargo, fue necesario reconstruir y renovar rutinas y costumbres, horarios y lugares de encuentro, formas de vestir y objetos de importancia y, también, reconocer a los hinchas que han ingresado en los últimos años a Blue Rain. De esta manera, me fue posible sostener y respaldar algunas de mis intuiciones en el desarrollo de mi trabajo de campo etnográfico al conocer y distinguir con anterioridad al club, a los hinchas y a la barra brava.

\section{EL CARNAVAL Y EL COMBATE DEMUESTRAN EL AGUANTE}

La festividad en las tribunas y los enfrentamientos en las calles son denominados por los hinchas como carnaval y combate, respectivamente. Entre los hinchas que forman los GOH, el carnaval y el combate no se contradicen, por el contrario, se complementan, ya que es fundamental "estar ahí», en las tribunas y en las calles. Por eso, los hinchas deben participar en el carnaval y el combate pues es necesario apoyar al equipo de fútbol y pelear contra los hinchas rivales. Finalmente, el carnaval y el combate demuestran el aguante entre los hinchas que forman las barras bravas.

\section{El carnaval}

Los hinchas que forman la barra brava, poco a poco, se acercan alrededor del estadio, arriban al escenario deportivo horas antes de iniciar el partido de fútbol. Los aficionados exhiben la ropa que los identifica como hinchas del club; unos pintan su cara con los colores y otros, tatúan en su cuerpo los emblemas. El encuentro de los hinchas posibilita, también la reunión de trapos, papel, sombrillas, instrumentos musicales y pirotecnia. En algunas ocasiones ensayan nuevas canciones, animando el lugar de encuentro. También, los hinchas promueven y permiten el consumo de bebidas embriagantes o sustancias psicoactivas, aunque no es generalizado, quienes no lo hacen, lo toleran. Luego de un par de horas, los dirigentes o los referentes de la barra brava, acompañados de sus partidarios y algunos líderes o jefes de parche, se encargan de trasladar — desde el lugar de reunión hasta las puertas del estadio— los trapos, el papel, las sombrillas, los instrumentos musicales y la pirotecnia. 
En las puertas del estadio, los referentes, sus partidarios y los jefes de parche esperan la autorización del ingreso por parte la Policía Metropolitana. Al lograr el permiso, los hinchas y todas sus pertenencias pasarán a una revisión exhaustiva por efectivos de la policía. El propósito de la requisa es evitar el ingreso de armas, bebidas alcohólicas y drogas ilegales, aunque algunos ya han ingerido licor y drogas. Después de la requisa se pueden dirigir a la tribuna y allí instalan o cuelgan los distintos trapos en diferentes lugares de la gradería. Las banderas horizontales o los frentes llevan el nombre de la barra brava, de los múltiples subgrupos o parches $^{2}$ que la forman o alguna frase que muestra su afiliación futbolística; son puestos de derecha a izquierda de la tribuna y pueden medir hasta 90 metros de largo y 5 de ancho. Se colocan en la baranda de seguridad y en las columnas que sostienen los techos de la gradería. Asimismo, las banderas verticales o las tiras se cuelgan de arriba a abajo de la tribuna y alcanzan dimensiones hasta de 30 metros de largo y 2,50 de ancho.

El papel y las sombrillas son distribuidos entre los líderes de los diferentes parches, quienes los reparten entre sus partidarios. La pirotecnia es concentrada entre los referentes de la barra brava y sus partidarios. Los bombos, los repiques, los zurdos, los redoblantes, los platillos y las trompetas son centralizados por La Banda del Bombo de Blue Rain; parche encargado de interpretar los instrumentos musicales durante el encuentro futbolístico. Después de ubicar los trapos, centralizar los instrumentos musicales y la pirotecnia y entregar el papel y las sombrillas, se espera el inicio del encuentro futbolístico. Antes de que el equipo pise el terreno de juego, los hinchas empiezan a aplaudir y a cantar esporádicamente. No obstante, en el momento que La Banda del Bombo empieza a interpretar los instrumentos musicales se impulsan las canciones (adaptadas al contexto del fútbol) y los saltos generalizados entre los hinchas en la gradería. Igualmente, se abren las sombrillas, se alista el papel y la pirotecnia.

Cuando el equipo pisa la cancha, La Banda del Bombo guía a los demás hinchas, quienes cantan más fuerte y sincronizan sus saltos. En ese momento, se lanza el papel y se enciende la pirotecnia; reciben a los jugadores con canciones, saltos, instrumentos musicales, trapos, sombrillas, papel y la pirotecnia. El propósito de este tipo de manifestaciones es exhibir su identidad futbolística y, además, manifestar su apoyo al grupo de jugadores, es decir, desde la tribuna los animan en su juego mediante, especialmente, los instrumentos y las canciones. «La música es aquí en el carnaval la protagonista y la acompañante de la celebración, la iniciadora, cómplice de la risa» (Bohórquez, 2014, p. 262). Este tipo de expresiones se pueden entender a través del carnaval en el contexto del fútbol. En este sentido,

\footnotetext{
2 El parche es una asociación de hinchas que se reúnen en torno a un origen territorial común, un referente histórico del equipo de fútbol o de la barra brava o son parte de otro grupo social.
} 
"Augusto» ${ }^{3}$ cuenta la organización y la función de las manifestaciones de los hinchas que forman la barra brava.

Se hace, como le decía, con recursos propios, con ideas propias, bueno pues no tan propias porque eso es copiado de otros países. Primero lo que se hacía era papeles, rollos, humo, bengalas. Con las prohibiciones entonces del humo se pasó a extintores. Y con la llegada de la televisión en todo lado, estas vainas de Europa, entonces se empezaron fue a hacer los tifos ${ }^{4}$, que aquí nunca resultaron porque no hay sentido de pertenencia, ni apropiación. Eso cuanto a la organización del carnaval. Y la intención es avivar al propio equipo, es asustar al rival. Y también mostrar como... pues supremacía, superioridad de mi barra a la del otro.

El papel es en pequeños trozos y en rollos, fácilmente se puede recolectar; los trapos son elaborados por los hinchas a partir de sus propias contribuciones y en algunas ocasiones, por aportes externos. Las sombrillas, la pirotecnia y los instrumentos musicales se adquieren con los recursos conseguidos por los referentes y los jefes de parche. Los trapos, el papel, las sombrillas, los instrumentos musicales y la pirotecnia en conjunto constituyen un ambiente festivo en la tribuna durante el encuentro futbolístico que, en palabras de "Augusto", organizan el carnaval de la barra brava. Además, el objetivo es empujar y animar al club, espantar e impresionar al equipo rival (e incluso a los hinchas rivales) y así, manifestar el predominio de lo propio (el club y la barra) sobre los otros (el club y la barra rival). En este aspecto, el ánimo que brinda la barra brava debe ser constante y dinámico durante el partido de fútbol. El ambiente festivo permite que los hinchas se diviertan mientras alientan a su club.

La Banda del Bombo se posiciona en el centro de la tribuna; desde ahí orientan la intensidad de los cantos y los saltos. En su alrededor se ubican los múltiples parches y algunos hinchas, particularmente hombres se estacionan en los rompeolas ${ }^{5}$ y otros sobre los vomitorios ${ }^{6}$, se agarran de las tiras para saltar mientras cantan. Por ejemplo, una de las canciones dice: «Esta es la banda de Millonarios, estamos locos de la cabeza ${ }^{7}$, se mueve para allá, se mueve para acá, esta es la banda más

\footnotetext{
3 Desde 1997 hasta 2007 fue integrante de Comandos Azules. Entre 2009 y 2016 se integró a Blue Rain. Los testimonios fueron recogidos en un diálogo sostenido con "Augusto» en febrero 11 de 2018.

4 Es un mosaico elaborado por los hinchas y desplegado en la tribuna que ocupan en el estadio, exhibiendo un símbolo del equipo o la barra brava. Se realiza con hojas de papel, plástico o banderas.

5 Son tubos de hierro, en forma de rectángulo, que han sido puestos en muchos escalones de la gradería, alcanzan una dimensión de dos metros de ancho por un metro de alto y se han instalado al interior para impedir o cortar las avalanchas.

6 Entrada-salida de la tribuna.

7 El canto original argentino dice: «Estamos todos de la cabeza» pero cuando se empezó a cantar en la tribuna, a finales de los noventa, muchos entendieron: «Estamos locos de la cabeza» y se mantiene de ese modo hasta el presente.
} 
loca que hay». Las canciones (buscan animar al equipo) y los saltos (de izquierda a derecha o viceversa) aumentan la temperatura en la gradería; por eso, muchos hinchas se quitan sus camisetas, exponiendo tatuajes; el escudo del club e incluso, los símbolos de la barra brava. Los saltos son armónicos, algunos hinchas se abrazan para conservar el equilibrio. Desde afuera se puede considerar que son saltos bruscos, fácilmente se cree que los hinchas se empujan o se golpean, pero no lo hacen ya que están pogueando ${ }^{8}$.

Por último, los hinchas que participen en la elaboración de los trapos, la adquisición de papel y pólvora y la compra de instrumentos musicales serán identificados por los referentes y los jefes de parches. De este modo, a través de su intervención, poco a poco, se involucrarán en múltiples actividades, constituyendo el orden interno y la jerarquía de la barra brava.

\section{El combate}

Los hinchas que forman Blue Rain elaboran canciones dirigidas contra los rivales futbolísticos en las que se burlan, los insultan, los desafían y los amenazan. Por ejemplo, en la historia deportiva de Millonarios, los hinchas constituyeron como rivales futbolísticos a Santa $\mathrm{Fe}^{9}, \mathrm{Cali}^{10}$, Junior ${ }^{11}$, América ${ }^{12}$ y $\mathrm{Nacional}^{13}$, por supuesto a los seguidores de esos equipos. En el contexto del fútbol, las rivalidades se manifiestan a través burlas, insultos, desafíos y amenazas; que se pueden materializar en enfrentamientos entre los hinchas de los diferentes clubes. En este aspecto, los hinchas que forman Blue Rain se han enfrentado a los integrantes de La Guardia Albi Roja Sur de Santa Fe, el Frente Radical Verdiblanco y Avalancha Verde Norte de Cali, el Frente Roji-Blanco Sur y La Banda de los Kuervos de Junior, el Disturbio Rojo Bogotá y el Barón Rojo Sur de América, y Los Del Sur y Nación Verdolaga de Nacional.

La competencia deportiva genera las rivalidades futbolísticas y los hinchas le agregan aspectos extrafutbolísticos: diferencias territoriales, pasionales, históricas, socioculturales, político-económicas e incluso, étnicas y sexuales, radicalizando aún más las rivalidades futbolísticas. De esta manera, los hinchas apropian esas diferencias y las expresan verbalmente, a través de las canciones, y físicamente,

\footnotetext{
8 Tipo de baile iniciado desde el género musical punk. En esta forma de danza, los sujetos se mueven según el ritmo de los instrumentos y levantan las piernas y los brazos. El baile se denomina pogo y participar implica poguear.

9 Equipo de la ciudad de Bogotá, capital de la República de Colombia.

10 Equipo de la ciudad de Santiago de Cali.

11 Equipo de la ciudad de Barranquilla.

12 Equipo de la ciudad de Santiago de Cali.

13 Equipo de Medellín.
} 
mediante el enfrentamiento. Los hinchas que forman las barras bravas pretenden un triunfo simbólico en la gradería y una victoria en los enfrentamientos. Dicho de otra manera, las barras bravas en las graderías muestran su capacidad mediante el despliegue de banderas, sombrillas, papel, instrumentos musicales y pirotecnia; exponiendo alegría y entretenimiento; un ambiente festivo, diferente al aburrimiento o a la amargura que resaltan contra sus rivales. Asimismo, con las canciones, los saltos, las burlas, los insultos, los desafíos y las amenazas.

En los estadios y en las calles, los hinchas que forman las barras bravas deben enfrentarse a sus rivales. En este caso, el cuerpo de los hinchas que permanecen es fundamental, ya que está expuesto a daños físicos. El uso del cuerpo (cabeza, brazos y piernas) y de sus extensiones (palos de madera, varillas, piedras, armas blancas ${ }^{14}$ y de fuego) son necesarias, pues se pretende una victoria en los enfrentamientos. De esta manera, las peleas producen lesiones, fracturas, múltiples heridas, e incluso, muertes. En ocasiones, los enfrentamientos involucran a miembros de la Policía Metropolitana, a quienes les es permitido ejercer más violencia que los hinchas que son señalados como violentos. En otras palabras, en los enfrentamientos se involucran múltiples actores, aunque solamente se ha nombrado a los hinchas y la policía. Los enfrentamientos se desarrollan cerca de los estadios, en los barrios y en las carreteras.

Desde la perspectiva de los hinchas, la permanencia en los enfrentamientos no es censurada; por el contrario, es ineludible, porque al no involucrarse pueden resultar agredidos por los rivales o declarados como ausentes por sus semejantes. Aunque si participan con la barra brava también pueden resultar golpeados, pero sus compañeros valorarán su permanencia. Las peleas entre los hinchas son denominadas como combate; una competencia corporal que exhibe las habilidades de los peleadores. De acuerdo con esto, Moreira (2006) — quien realizó su trabajo de campo etnográfico con la hinchada del Club Atlético Independiente de Avellaneda- destaca que el combate permite distinguir a los simpatizantes del mismo equipo y los enfrentamientos producen una sucesión continua de provocaciones y duelos entre las hinchadas rivales, con el objetivo de mantener y ratificar su honor. En este sentido, «Augusto» narra la experiencia del combate:

El combate tiene tres como finalidades digo yo, una por venganza, otra por territorialidad y otra por ir a buscar las banderas. [...] El combate, al igual que, pues la fiesta, es una manera también de demostrar superioridad, de imponerse ante la barra rival. En un principio se hacía cuerpo a cuerpo, con los puños, usando nada más que el cuerpo. Ya con el tiempo se empezaron a incluir armas blancas, armas de fuego y pues cada vez se hizo más peligroso.

\footnotetext{
14 Desde cuchillos hasta machetes.
} 
[...] El combate se da de manera esporádica, simplemente cuando uno de camino al estadio se presenta la situación, sin haberlo planeado previamente, o saliendo del barrio o bueno, por casualidad, simplemente se encontraron los dos bandos y ya se generó un espacio propicio, un ambiente propicio para eso, pues para combatir. En otras ocasiones, se planea con anterioridad, puede ser en una de las reuniones, se programa, se cuadra, se hace inteligencia al rival y se va en busca de ellos. Otras situaciones es cuando uno no es quien lo está planeando sino uno es el emboscado pues simplemente uno está reunido o va camino al estadio y es atacado por la barra rival.

Lo dicho por "Augusto» expone los propósitos de los enfrentamientos físicos: todo ataque o emboscada se debe responder al instante; si no es posible, debe planearse, es decir, sigue el orden de la ley del talión ${ }^{15}$. Los combates buscan sobreponerse ante el rival y, así, constituir un área de influencia de los hinchas que forman la barra brava, y por último, se busca arrebatar los bienes de los rivales, una manera de demostrarles su inferioridad. Los enfrentamientos pueden ser ocasionales o concebidos; sin importar si es lo primero o lo segundo, es necesario permanecer en el lugar de la pelea. Uno de los aspectos a resaltar en el testimonio de "Augusto» es la transformación de los combates, ya que inicialmente eran regulares los cabezazos, los puños y las patadas, quizá el uso de palos de madera, varillas, piedras; pero se normalizó el uso de armas blancas y de fuego. Además, en el presente, los enfrentamientos no se realizan en los estadios sino en diferentes barrios de Bogotá e incluso, en carretera.

Este tipo de conductas son entendidas - por aquellos que no integran las barras bravas - como acciones violentas en el contexto del fútbol, comportamientos que deben ser controlados o reprimidos por la policía. La violencia se interpreta de diferente manera a partir de la posición en la que se ubica: ejecutor, víctima o testigo: el primero la considera legítima, y los segundos, ilegítima (Riches, 1988). No obstante, para los hinchas que forman las barras bravas, las emboscadas o los robos no son calificados como una acción ilegítima, pues los ataques o los asaltos se deben responder de forma semejante y si es posible, causar mayor daño a los rivales. Por eso, se dio importancia al uso de armas, ya que el objetivo es reducir al rival a su mínima expresión. De esta manera, los hinchas que forman la barra brava buscan demostrar que son "valientes", distintos del temor o a la cobardía que destacan contra sus rivales.

Por último, los hinchas que participen en las emboscadas o los robos a los rivales, o mejor, quienes permanezcan en el lugar en el que son atacados o defiendan los trapos, serán identificados por los referentes y los jefes de parches. De esta manera,

15 Ojo por ojo, diente por diente: la ofensa o el delito debe ser vengado o reparado de forma semejante. 
a través de su participación y permanencia, paso a paso, se insertarán en el orden interno y la jerarquía de la barra brava.

\section{El aguante}

El 5 de enero de 1983 se utilizó «oficialmente» la expresión aguante. En esa fecha fue asesinado Raúl Servín Martínez, hincha de Boca Juniors ${ }^{16}$. Antes de disparar al parecer - los homicidas gritaron: "iAguante Quilmes!» ${ }^{17}$ (Alabarces, 2012). De acuerdo con lo mencionado, es posible seńalar que el aguante es un término que se originó y se popularizó entre los hinchas de Argentina. Posteriormente, a partir de la categoría del aguante fueron realizadas múltiples investigaciones que indagaron sobre la lógica de la violencia en las hinchadas. Entre esas investigaciones se destacan: Moreira (2007), Garriga (2010), Zambaglione (2011) y Alabarces (2012). Una de las conclusiones de mayor relevancia es: el aguante implica poner el cuerpo, es decir, es necesario enfrentarse a puños con el otro (el enemigo) ya que se identifica con una camiseta distinta de la propia. Además, las reflexiones de Dodaro (2006) y Gil (2007) muestran que, las nociones de los hinchas en la hinchada son contextuales, al transformarse a partir de múltiples situaciones, y así, el aguante no es estático.

En este aspecto, Cabrera, Garriga y Murzi (2018) plantean una discusión alrededor del aguante, ya que es posible construir una interpretación sobre los hinchas en las hinchadas, pero, al mismo tiempo, puede limitar su análisis. Asimismo, otras investigaciones se han realizado en otros contextos, como el chileno y el colombiano, que parten de la noción emic del aguante. De este modo, Abarca (2001) realizó su trabajo de campo con hinchas de Colo Colo y Castro (2018) con Blue Rain de Millonarios. De este modo, Abarca (2001) explica que, el aguante «representa un principio aglutinador de la experiencia, definido como el arte de no escapar, de soportar lo que venga» (p. 115), y Castro (2018) afirma que, en la barra brava, las expresiones festivas y los comportamientos violentos de los hinchas hacen el aguante, un estilo de vida que instituye una forma de identidad y un tipo ritual que exhibe conductas regulares, define la pertenencia, la participación, la distinción de los hinchas y se asumen las rivalidades.

En relación con esto, es posible señalar que el aguante fue adoptado y adaptado por distintas barras bravas de Hispanoamérica. Por eso, la noción y la experiencia emic del aguante aún pueden ser usadas como lente interpretativo que permita comprender (desde la perspectiva de los hinchas que forman las barras bravas) sus prácticas, o por lo menos, algunos de los comportamientos que exhiben en los estadios

16 Club Atlético Boca Juniors de la Ciudad Autónoma de Buenos Aires.

17 Quilmes Atlético Club de la provincia de Buenos Aires. 
y en las calles. Desde luego, cada categoría de análisis —emic o etic- permitirá alcances de comprensión e interpretación, pero será limitada en otros aspectos, pues la conceptualización totalizadora o multiabarcadora en ciencias sociales puede ser cuestionada a partir del surgimiento de campos emergentes en la investigación en estudios sociales o culturales e incluso, por los grupos sociales. De este modo, los hinchas que participen en el carnaval y en el combate son reconocidos por los referentes y los jefes de parches, es decir, la participación y la permanencia permite la particularización de los hinchas en la barra brava, quienes serán calificados de hinchas con aguante.

El carnavaly el combate son nociones y vivencias distintas, pero, al mismo tiempo, son complementarias pues en conjunto demuestran el aguante entre los hinchas que forman las barras bravas. Esa demostración le posibilita al hincha dejar el anonimato al ser distinguido por sus semejantes y, también, por los rivales. Además, el aguante evidencia una disposición del hincha de participar y de permanecer en las distintas actividades que promocionan y promueven los dirigentes y los líderes de los parches. En otras palabras, el hincha, sin importar las circunstancias, les advierte que él está dispuesto a participar y a permanecer en los que ellos convoquen. Así, el aguante se constituye en un compromiso en el carnavaly en el combate, compromiso que lo circunscribe a la barra brava al ser aceptado por los referentes y los jefes de parche. En ese sentido, «Augusto» me cuenta sobre el significado del aguante:

El aguante está relacionado con, la misma palabra lo dice, con aguantar. Entonces puede ser en varias circunstancias, puede ser aguantar al equipo, o sea, estar ahí, al frente, a pesar de los malos resultados, hasta los últimos momentos. También puede uno aguantar las banderas, aguantar en un combate, es como ese nivel de resistencia ante las dificultades ¿¿í́? Entonces, va asociado al coraje de la barra, de ser parao ${ }^{18}$, en cuanto al combate, de aguantar en un combate o del amor, cuando uno aguanta al equipo, de la incondicionalidad.

A partir el relato de «Augusto» surge una pregunta ¿qué es el aguante? Y la respuesta es sencilla: aguantar, pero ¿qué es aguantar? Aguantar implica soportar los resultados adversos del equipo que siguen; mantener la presencia en la tribuna en lo particular y en lo general, durante el encuentro futbolístico y en la totalidad del campeonato. Asimismo, conservar las pertenencias de la barra brava: camisetas, sombrillas, instrumentos musicales, especialmente, los trapos y permanecer en el lugar de la pelea, evadiendo las agresiones rivales y respondiendo de la misma forma, y si es posible, más fuerte. De esta manera, el aguante es asociado a la resistencia de los hinchas ante las adversidades, al esfuerzo en la preparación del carnaval,

18 Se refiere a mantenerse en el lugar de la pelea y ser capaz de responder a los ataques adversarios. 
a la valentía al permanecer en el combate. A partir de lo anterior, el aguante es aceptado y reiterado por los hinchas que forman las barras bravas.

El aguante es incluyente y excluyente en la barra brava; es incluyente porque reúne a los hinchas que participan y permanecen en las actividades festivas y permanecen en el lugar de la pelea. Y es excluyente porque prescinde de los hinchas que no participan en el carnaval y no permanecen en el combate. Dicho de otra manera, el aguante es para los hinchas que forman la barra brava. Asimismo, a los rivales se les niega el aguante; por eso son calificados de amargos y cobardes; amargos porque no se siente que apoyan a su equipo de fútbol y cobardes pues huyen de los enfrentamientos. De este modo, el aguante permite demostrar la alegría y la valentía de los hinchas que forman las barras bravas, opuesta a la amargura y a la cobardía de los rivales, de aquellos que forman otras barras bravas. El aguante es posible si es expuesto a los otros hinchas del mismo equipo y de otros clubes. "Gordo Lan»" ${ }^{19}$ amplía la perspectiva sobre el aguante, relacionado con el carnaval y el combate:

El aguante es lo que yo he tenido que llevar durante veinte años. Desde que me despierto hasta que me acuesto. El aguante es todo eso que le he depositado a Millonarios. Todo eso es aguante, en un viaje, en un partido, en todas las cosas que, en las cuales le he entregado a Millonarios. Ahí veo el aguante, en la tribuna, en los viajes, en cualquier cosa. Un aguante, hasta me he aguantado un tiro en la boca, eso es tener aguante, y seguir todavía de pie. Tener aguante es perder un partido, estar de últimas en la tabla y el primer semestre es estar de primeras, eso es tener aguante. Tener aguante es ver y sońar que Millos va a ser campeón y perder. Tener aguante es todo eso, tener aguante es eso. Todo lo que me ha tocado pasar en mil millones de viajes, todo el aguante que se deposita, el aguante va dentro de nosotros. El aguante es lo que nos hace ser, lo que nos representa y nos define como barras bravas.

El aguante con la rivalidad se ve todo el tiempo. El aguante, por lo menos, quien alienta los noventa, quien se escucha más duro dentro de la cancha. Cuando, por lo menos, dejaban entrar visitantes y se llenaban las dos tribunas, se partía el estadio en dos. Ahí se veía cuál era el más aguante, la mejor salida, el que alentaba más en los noventa, quien se escuchaba más, ese es el aguante. En una pelea se ve el aguante, por lo menos en una pelea se ve mucho. Se desgasta uno terrible pues el aguante es resistir. Así a usted le den roca ${ }^{20}$, palo ${ }^{21}$, usted ahí con el aguante, está parado ${ }^{22}$ en la suya y no da, no da un paso a atrás, [eso] es tener aguante. La pelea

19 Desde 2001 hasta 2005 fue integrante de Comandos Azules. Luego, entre 2006 y 2009 hizo parte de Blue Rain. Desde 2009 se integró, nuevamente a Comandos Azules. El testimonio fue recogido en un diálogo sostenido con «Gordo Lan» en marzo 25 de 2018.

20 Piedras.

21 Palo de madera.

22 Se mantiene en el lugar de la pelea. 
con el rival, tener aguante es pararme en la calle solo, ver a cinco y decir: «Bueno gonorrea $^{23}$, me voy a montar de un palo y sabe que me voy a dar con los cinco». Tengo aguante, me le banco ${ }^{24}$ lo que sea, [eso] es tener aguante.

El testimonio de «Gordo Lan» logra explicar que la demostración del aguante es permanente está relacionado con la identificación futbolística y lo que esta identificación implica, por ejemplo, la asistencia a las tribunas siguiendo al equipo de local y visitante, sin importar el marcador de los partidos; soportar las agresiones y mantenerse dispuesto a pelear. Dicho de otra manera, las múltiples experiencias a partir del carnaval y el combate demuestran el aguante, una decisión y un compromiso voluntario constituyente de una identidad específica y representativa. "Gordo Lan» reitera que, el aguante se materializa a través de las canciones y los saltos, produciendo un impacto en el terreno de juego y en las otras tribunas, particularmente las que ocupan los hinchas que forman las barras bravas rivales. Al mismo tiempo, el aguante permite recurrir a lo que sea necesario para derrotar al rival, sin importar la desventaja que se asuma en la pelea.

Por último, la participación y la permanencia en el carnaval y en el combate les permite a los hinchas ser identificados e individualizados, es decir, salir del anonimato en la barra brava al demostrar su aguante. La participación y la permanencia permite organizar el orden interno y la jerarquía entre los antiguos y los nuevos hinchas. Así, una posición a partir de la decisión y el compromiso.

\section{EL ORDEN INTERNO Y LA JERARQUÍA}

Blue Rain es integrada por referentes, jefes de parche, partidarios y chinos o pelaos. Los referentes comúnmente superan los veintiocho años; los llaman cuchos o viejos, pues pertenecen a la barra brava desde años atrás y su trayectoria les ha permitido alcanzar notoriedad y liderazgo. Los referentes pueden contactar a directivos del club, patrocinadores, periodistas y autoridades oficiales, entre otros actores que pueden relacionarse con el fútbol. La autoridad de los referentes se visibiliza en el compromiso que logra de los distintos parches. Los jefes de parche son los líderes de los subgrupos de la barra brava y promueven la participación en las distintas actividades que proponen los referentes y a su vez, promocionan las suyas. Los partidarios son los hinchas que respaldan a los referentes y a los jefes de parche; algunos hinchas — de forma despectiva - los llaman los carros, ya que llevan y traen órdenes o encargos. Y los chinos o los pelaos son los miembros más jóvenes de la barra brava

23 En este contexto, se refiere a tomar la decisión de afrontar el enfrentamiento, recurriendo a un lenguaje soez.

24 Soportar. 
y, usualmente, se integran a los parches. Ellos participan en las diferentes acciones que proponen los jefes y los referentes. En Colombia, a los jóvenes se les llama chinos o pelaos, una denominación que los califica como inexpertos.

Los referentes, los jefes de parche, los partidarios y los chinos o los pelaos se encuentran en horarios diferentes de los encuentros futbolísticos de su club. Los encuentros son realizados lejos del estadio o del sitio de entrenamiento del equipo. Por eso, se reúnen en parques, plazoletas o canchas de microfútbol, lugares ubicados en barrios de influencia de la barra brava. Además, los sitios escogidos cambian cada semana pues pretenden conservar algunas condiciones de seguridad ante una posible infiltración o una emboscada por parte de hinchas que forman barras bravas rivales. Durante la semana se pueden desarrollar dos reuniones: el primer encuentro es cerrado y el segundo es abierto. En el primero asisten los referentes, los jefes de parche y algunos partidarios. En el segundo, asisten otros partidarios, son convocados los chinos, quienes pertenecen a distintos parches, y también, a los hinchas que desean participar en las actividades de la barra brava, aunque no pertenezcan a ningún subgrupo.

En el encuentro entre los referentes y los jefes de parche acuerdan una serie de objetivos y división del trabajo que posibilite: comprar tela, elaborar y pintar nuevos trapos o el mantenimiento de los existentes. De forma semejante ocurre con los instrumentos musicales interpretados por La Banda del Bombo, es decir, su conservación o su adquisición. Asimismo, la búsqueda y la compra de papel, sombrillas, humo de colores y pirotecnia. Luego, en el encuentro que es convocado por los referentes y los jefes de parche se les anuncia a los partidarios y a los pelaos y a los demás hinchas, sobre lo acordado en la reunión de los primeros y la necesidad de participar, de alguna forma, en el mantenimiento de los trapos, las sombrillas y los instrumentos musicales o la necesidad de elaborarlos o adquirirlos nuevamente. Igualmente, la colaboración, especialmente en dinero para la consecución de papel, humo de colores y pirotecnia. Y si el encuentro futbolístico es de visitante, empiezan a promocionar y a organizar el viaje a la ciudad donde el equipo va a jugar.

Asimismo, entre los referentes, los jefes de parche, los partidarios y los chinos se organizan con el propósito de entrenar su cuerpo para la pelea callejera, en diferentes deportes de combate. Si lo hacen, quienes se comprometan tendrán una nueva reunión para cumplir dicho objetivo. El entrenamiento es fundamental si se quiere alcanzar una victoria en el enfrentamiento. No obstante, se popularizó el uso de palos de madera, varillas, piedras, armas blancas y de fuego, utilización que ha modificado las peleas y ha iniciado una preocupante lista de crímenes. En este aspecto, entre 2001 y 2019, han sido asesinadas alrededor de 173 personas en Colombia, una cifra (no oficial) que involucra a hinchas que forman las barras bravas. Además, en algunas de las barras bravas de Colombia se han construido 
múltiples conflictos internos, disputas que han concluido en relevos generacionales y también, en divisiones internas, creando una nueva barra del mismo club de fútbol.

El carnaval se expresa en la tribuna y el combate se evidencia en las calles, en los barrios y en las carreteras. Sin embargo, es posible que la festividad se manifieste en las calles o en los barrios y los enfrentamientos se desenvuelvan en las tribunas. Este tipo de manifestaciones no son accidentales pues se han concebido con anterioridad en las reuniones, especialmente las relacionadas con el carnaval, pues en lo vinculado al combate es probable que se inicien enfrentamientos, en algunas ocasiones de manera fortuita y en otras, se ha planeado. Los referentes, los jefes de parche y los partidarios impulsan en la tribuna el canto y el salto durante el encuentro futbolístico y en las calles, permanecen en el lugar de la pelea, motivando a los chinos a comprometerse en la participación en el carnaval y la permanencia en el combate. En este sentido, Panfichi (1999) —en su trabajo de investigación con Comandos Svr de Alianza Lima y Trinchera Norte de Universitario de Deportes- afirma que, la masculinidad agresiva define a los líderes, quienes, rodeados de otros hinchas, «tienen la responsabilidad de vigilar en las graderías que todos canten desaforadamente o 'guerreen' en defensa de sus colores» (p. 158).

Los referentes, los jefes de parche y los partidarios se han encargado voluntariamente de promover y participar en las diferentes actividades de la barra brava ya que mediante sus orientaciones adquieren prestigio, notoriedad y, además, ellos se convierten en un ejemplo a seguir para los pelaos. Igualmente, adquieren una autoridad que les posibilita tomar las decisiones necesarias y ordenarles a los chinos y a los demás hinchas, cumplir con lo relacionado al carnaval y al combate. Por lo tanto, el aguante constituye a los referentes, a los jefes de parche y a los partidarios pues sus vivencias y relatos son la demostración de su compromiso y su antigüedad. Esas experiencias se van acumulando, pero deben renovarse partido tras partido, no es posible heredarlas; logrando la identificación y la distinción entre los hinchas que integran la barra brava, hinchas rivales y autoridades oficiales. La promoción y la participación de los referentes y los jefes de parche en las distintas actividades establece el orden interno ya que la barra brava es un grupo social jerárquico.

Esa promoción y esa participación no son asumidos por todos los hinchas pues no todos tienen la misma determinación por diferentes decisiones, motivos o circunstancias. Además, los referentes impiden que los jefes de parche asciendan en la jerarquía interna; quienes, a su vez, frenan a los partidarios y a los chinos, quienes quieren salir del anonimato y ascender en la jerarquía. Y los pelaos exigen a los hinchas que pretenden integrarse a la barra brava o al parche, participar activamente en el carnavaly en el combate. Sin embargo, los referentes y los jefes de parche les otorgan ciertos beneficios a quienes muestran la pretensión de ascender en la jerarquía, 
de una u otra manera los neutralizan. Si se mantiene su aspiración, deben demostrar creatividad e ingenio en el planteamiento de particulares acciones relacionadas con el carnaval y el combate. Los referentes y los jefes de parche pueden conservar su posición en la jerarquía de la barra brava si renuevan la demostración de su compromiso partido tras partido. De esta manera, el orden interno y la jerarquía están determinados por quien ejerce la autoridad en la barra brava.

Los referentes, los jefes de parche y los partidarios deben demostrarles su aguante a los chinos y a los hinchas del mismo equipo, a los hinchas rivales y a las autoridades deportivas y oficiales. Los referentes y los jefes de parche han logrado posicionarse a partir de la promoción y la participación en las diferentes actividades de la barra brava. Por eso, reciben pases de entrada al estadio, puestos en los buses para los viajes, indumentaria deportiva oficial e incluso, la posibilidad de obtener distintos puestos de trabajo, entre otros beneficios. Aunque la posición no se comparte, los referentes y los jefes de parche distribuyen parcialmente los beneficios conseguidos y así, conservar el orden interno. El manejo de los recursos económicos y los contactos son propiedad de los referentes, quienes promueven y participan enérgicamente en todas las actividades y están presentes en las distintas circunstancias de la barra brava, sean favorables o esencialmente adversas.

\section{Conclusiones}

En Colombia, las barras bravas se organizaron en la década de 1990. Los GOH mostraron innovadas manifestaciones para alentar a su club de fútbol y de enfrentarse a los rivales. Las barras bravas exponen dos comportamientos regulares: el carnaval y el combate, componentes del aguante, una decisión y un compromiso que les permite relacionarse, vincularse, asociarse y ordenar su jerarquía a partir de la promoción y la participación en las diferentes actividades. La demostración del aguante les otorga ciertos beneficios, beneficios que distintos hinchas desean alcanzar e incluso, controlar. En otras palabras, este artículo expuso las formas de demostrar el carnaval, el combate y el aguante entre los hinchas que integran una barra brava de Bogotá, maneras que posibilitan el orden interno y la jerarquía. Lo expuesto en el artículo amplió la mirada sobre la constitución del orden interno y la jerarquía entre los hinchas que forman una barra brava de Bogotá.

Las nociones-experiencias de carnavaly combate posibilitan comprender lo dicotómico de la realidad social de los hinchas. Por un lado, «nosotros» del mismo club, y por otro lado, «ellos», de otro club, desde lo propio se distingue y se distancia de lo ajeno. «Nosotros» permite alentar a «mi club», cohesionando al Grupo Organizado de Hinchas. Esa cohesión también posibilita ir en la búsqueda de «ellos» para enfrentarlos. En otras palabras, los hinchas que forman Blue Rain o Comandos 
Azules se identifican futbolísticamente con Millonarios, alrededor de esa afición se relacionan y se vinculan para alentar al club. La identificación por Millonarios implica, al mismo tiempo, la distinción y el distanciamiento con otros equipos, por ejemplo, Santa Fe, Cali, Junior, América o Nacional. Y la pertenencia a Blue Rain o a Comandos Azules trae consigo la aceptación de las rivalidades y la posibilidad de los enfrentamientos contra los hinchas que pertenecen a La Guardia Albi Roja Sur, Frente Radical Verdiblanco, Avalancha Verde Norte, Frente Roji-Blanco Sur, La Banda de los Kuervos, Disturbio Rojo Bogotá, Barón Rojo Sur, Los Del Sur o Nación Verdolaga.

En este aspecto, las posibilidades para explicar el carnaval y el combate desde la posición de los hinchas, lo emic, y desde la perspectiva del investigador, lo etic, aún no se han agotado. Quizá al realizar nuevas investigaciones sobre la festividad y la violencia, la explicación sobre el aguante arroje nuevas interpretaciones. Aunque la noción-experiencia del aguante tiene su origen en Argentina y fue adoptado por distintas barras bravas en Hispanoamérica, su adaptación fue particular, al depender de cada uno de los escenarios y las situaciones asumidas por los actores mediante la participación en la festividad y la permanencia en las peleas. El aguante es necesario entenderlo desde las nociones y las experiencias de los hinchas y, también, interpretarlo desde nociones externas a la barra brava, permitiendo comprender las semejanzas y las diferencias entre los clubes y sus hinchas, y las diferentes acciones repetitivas y habituales, caracterizadas por su valor simbólico, que exponen los jugadores y los hinchas.

En este sentido, es necesario ampliar el entendimiento sobre el ordenamiento interno y las disputas al interior de los grupos sociales denominados barras bravas ya que la homogeneidad de la barra brava es discutida puesto que los procesos de jerarquización y autoridad no son uniformes, al depender los contextos constituyentes. Igualmente, es necesario explicar el apoyo que necesitan los referentes y los jefes de parche para mantenerse en su posición, requiriendo lealtad por parte de los partidarios y los chinos, quienes exaltan su autoridad y esperan una retribución. Una lealtad que se obtiene a partir de ayudas, protección y obediencia o sumisión, conservando la posición de los referentes. Además, el ejercicio de coacción y la coerción de los referentes sobre los partidarios y los jefes de parche; de los jefes de parche sobre los partidarios y los chinos o pelaos. Los referentes y los jefes de parche esperan el cumplimiento de sus disposiciones, advirtiendo a jefes de parche, partidarios y a los chinos o pelaos para que se efectúen. 


\section{REFERENCIAS}

Abarca, H. (2001). Crónicas del aguante. En J. Olavarría, Hombres: identidad/es y violencia (pp. 111-124). Santiago: Facultad Latinoamericana de Ciencias Sociales.

Alabarces, P. (2012). Crónicas del aguante: Fútbol violencia y politica. Buenos Aires: Capital Intelectual.

Aragón, S. (2007). "Los trapos se ganan en combate»: una mirada etnográfica sobre las representaciones y prácticas violentas de la "barra brava» de San Lorenzo de Almagro. Lanús: Antropofagia.

Bohórquez, C. (2014). La música como dimensión simbólica del Carnaval. En M. González, Carnavales y nación. Estudio sobre Brasil, Colombia, Costa Rica, Cuba y Venezuela (pp. 256-267). Bogotá: Corporación de Estudios Interculturales Aplicados.

Cabrera, N. (2017). Un quiebre en el campo. Apuntes epistemológicos y ético-metodológicos para el abordaje etnográfico en contextos de violencia(s). Cuadernos de Antropología Social, (46), 49-66.

Cabrera, N., Garriga, J. y Murzi, D. (2018). ¿El ocaso del aguante? Reinterpretando la violencia en el fútbol argentino. Recuperado el 12 de febrero de 2020, de Revista de Ciencias Sociales: http:/www.revistacienciasociales.cl/ojs/index.php/publicacion/ article/view/129/107

Castro, J. (2018). Alentando y peleando se tiene «aguante»: la construcción de la identidad en una barra brava. En R. Jaramillo, G. Gómez y J. Castro, Fútbol y barras bravas: análisis de un fenómeno urbano (pp. 323-462). Bogotá: Siglo del Hombre Editores / Universidad Nacional de Colombia.

Dodaro, C. (2006). Aguantar no es puro chamuyo. Estudio de las transformaciones en el concepto nativo. En P. Alabarces, Hinchadas (pp. 105-125). Buenos Aires: Prometeo Libros.

Garriga, J. (2010). Haciendo amigos a las piñas. Violencia y redes sociales de una hinchada de fútbol. Buenos Aires: Prometeo Libros.

Garriga, J. (2012). "Josecito, te van a cagar a pińas». Miedo y sentido común en el trabajo de campo. Estudios en Antropología Social(2), 15-23.

Geertz, C. (1989). El antropólogo como autor. Barcelona: Paidós.

Geertz, C. (2003). La interpretación de las culturas. Barcelona: Gedisa.

Gil, G. (2007). Hinchas en tránsito: Violencia, memoria e identidad en una hinchada de un club del interior. Mar del Plata: Editorial de la Universidad de Mar del Plata.

Goldenberg, M. (1999). A Arte de Pesquisar: como fazer pesquisa qualitativa em Ciências Sociais. Río de Janeiro: Record.

Guber, R. (2001). La etnografía: Método, campo y reflexividad. Bogotá: Norma.

Moreira, V. (2006). Trofeos de guerra y hombres de honor. En P. Alabarces, Hinchadas (pp. 75-89). Buenos Aires: Prometeo Libros.

Moreira, V. (2007). Etnografía sobre el honor y la violencia de una hinchada de fútbol en Argentina. Revista Austral de Ciencias Sociales, 13, 5-20. https://doi.org/10.4206/rev. austral.cienc.soc.2007.n13-01 
Panfichi, A. (1999). Representación y violencia en el fútbol peruano: barras bravas. Contratexto, (12), 151-161. https://doi.org/10.26439/contratexto1999.n012.726

Sanabria, F. (2009). Manderlay, Grace and Freedom o la tentación de hacer el bien en antropología. En F. Sanabria y H. Salcedo, Ficciones sociales contemporáneas (pp. 19-31). Bogotá: Universidad Nacional de Colombia.

Zambaglione, D. (2011). Hinchadas: Cuerpos sociales, cuerpos con aguante. Lúdica Pedagógica, 2(16), 22-29. https://doi.org/10.17227/ludica.num16-1354 